\title{
Perampanel, an AMPAR antagonist, alleviates experimental intracerebral hemorrhage-induced brain injury via necroptosis and neuroinflammation
}

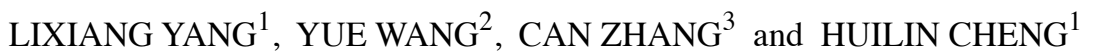 \\ ${ }^{1}$ Department of Neurosurgery, Zhongda Hospital, School of Medicine, Southeast University, Nanjing, \\ Jiangsu 210009; ${ }^{2}$ Department of Neurosurgery, 904th Hospital of Joint Logistic Support Force of PLA, \\ Wuxi Clinical College of Anhui Medical University, Wuxi, Jiangsu 214044; ${ }^{3}$ Department of Neurosurgery, \\ The Second People's Hospital of Hefei, Hefei, Anhui 230011, P.R. China
}

Received March 10, 2021; Accepted May 11, 2021

DOI: $10.3892 / \mathrm{mmr} .2021 .12183$

\begin{abstract}
Spontaneous intracerebral hemorrhage (ICH) is a subtype of stroke with high mortality and morbidity due to the lack of effective therapies. The alpha-amino-3-hydroxy-5-met hyl-4-isoxazolepropionic acid receptor antagonist perampanel has been reported to alleviate early brain injury following subarachnoid hemorrhage and traumatic brain injury by reducing reactive oxygen species, apoptosis, autophagy, and necroptosis. Necroptosis is a caspase-independent programmed cell death mechanism that serves a vital role in neuronal cell death following ICH. However, the precise role of necroptosis in perampanel-mediated neuroprotection following ICH has not been confirmed. The present study aimed to investigate the neuroprotective effects and potential molecular mechanisms of perampanel in $\mathrm{ICH}$-induced early brain injury by regulating neural necroptosis in C57BL/6 mice and in a hemin-induced neuron damage cell culture model. Mortality, neurological score, brain water content, and neuronal death were evaluated. The results demonstrated that perampanel treatment increased the survival rate and neurological score, and increased neuron survival. In addition, perampanel treatment downregulated the protein expression levels of receptor interacting serine/threonine kinase (RIP) 1, RIP3, and mixed lineage kinase domain like pseudokinase, and of the cytokines IL-1 $\beta$, IL- 6 , TNF- $\alpha$, and $N F-\kappa B$. These results indicated that perampanel-mediated inhibition of necroptosis and neuroinflammation ameliorated neuronal death in vitro and in vivo following $\mathrm{ICH}$. The neuroprotective capacity of perampanel was partly dependent on
\end{abstract}

Correspondence to: Dr Huilin Cheng, Department of Neurosurgery, Zhongda Hospital, School of Medicine, Southeast University, 87 Dingjia Bridge Road, Nanjing, Jiangsu 210009, P.R. China

E-mail: dnuch1123@163.com

Key words: perampanel, early brain injury, intracerebral hemorrhage, necroptosis, neuroinflammation the PTEN pathway. Taken together, the results of the present study demonstrated that perampanel improved neurological outcomes in mice and reduced neuronal death by protecting against neural necroptosis and neuroinflammation.

\section{Introduction}

Spontaneous intracerebral hemorrhage (ICH) has the highest mortality rate among stroke subtypes, accounts for $15-20 \%$ of all stroke types, and has an increased incidence in elderly patients (1-3). Acute ICH due to a large intracranial hematoma is associated with high morbidity and mortality, as it can lead to primary brain injury through the destruction of brain tissue and the high intracranial pressure (ICP) that results from the large hematoma $(4,5)$. Previous studies revealed that craniotomy for hematoma evacuation is an effective therapy for limiting primary brain damage and decreasing ICP following ICH, which is of substantial interest $(4,6,7)$. However, craniotomy for hematoma evacuation shows no clinical benefit to patients, no improvement in long-term outcomes, and rarely affects neurological recovery (8). Increasing evidence shows that red blood cell debris, hemoglobin, its degradation products, and blood components trigger secondary brain injury following $\mathrm{ICH}$ and contribute to a series of damaging events, including neuroinflammation, brain edema, oxidative stress, blood-brain barrier damage, and neuronal death (9-14). In recent years, an increasing number of studies have been conducted with a focus on the mechanisms underlying $\mathrm{ICH}$-induced secondary injury to investigate better therapeutic targets for $\mathrm{ICH}(6,15)$.

A previous study has reported that neuroinflammation has a key role in the progression of $\mathrm{ICH}$-induced brain injury and is characterized by an innate immune response and subsequent inflammatory cytokine production (16). The neuroinflammatory mechanisms include activation of microglia, the resident macrophages in the brain, and other blood-derived immune cells (9). Activated microglia/macrophages and peripheral blood-derived immune cells release proinflammatory cytokines, including tumor necrosis factor (TNF-) $\alpha$, interleukin (IL-) $1 \beta$, chemokines, free radicals, and other toxic chemicals, which ultimately leads to brain edema 
and neuronal death $(17,18)$. ICH-induced neuronal death was initially divided into two different categories, necrosis and apoptosis. Necroptosis, a recently discovered form of necrosis, is a caspase-independent mechanism of programmed cell death and serves a vital role in neuronal cell death following ICH $(19,20)$. Previous studies have demonstrated that necroptosis inhibition can significantly improve brain injury outcomes after ICH $(21,22)$. Therefore, targeting neuroinflammation and necroptosis has become a major goal of ICH treatment.

Glutamate is the most important and widely distributed excitatory neurotransmitter in the brain and predominantly binds to alpha-amino-3-hydroxy-5-methyl-4-isoxazolepropionic acid (AMPA), kainate, and N-methyl-D-aspartate ionotropic receptors (23). Overexpression of glutamate and overactivation of its receptors contribute to neuroinflammation, tissue damage, or neuronal death following $\mathrm{ICH}$, traumatic brain injury, or acute and chronic pain $(24,25)$. Perampanel is a noncompetitive antagonist of AMPA receptor (AMPAR), a subtype of ionotropic glutamate receptor (26). Previous studies have revealed that perampanel can exert neuroprotective effects and improve brain injury outcomes after traumatic brain injury, and its mechanisms of action may be related to neuronal necroptosis and antioxidative and anti-inflammatory activity $(24,27,28)$. However, the effects of perampanel on ICH in vitro or in vivo remain unclear, and whether the underlying molecular mechanisms involve neuronal necroptosis and neuroinflammation has not been investigated. Wang et al (29) reported that the PTEN signaling pathway was crucial for regulating cell death by necroptosis and apoptosis. Guido et al (30) also demonstrated that the estrogen receptor (ER) $\beta / P T E N$ signaling pathway induced cell death in TCAM2 cells by autophagy and necroptosis. In a subarachnoid hemorrhage model, mesenchymal stem cell-derived extracellular vesicles promoted neuronal survival and alleviated early brain injury via the PTEN/AKT pathway (31).

The present study therefore investigated the effects of perampanel on ICH in vitro and in vivo, and explored its potential molecular mechanisms with a focus on the PTEN signaling pathway.

\section{Materials and methods}

Animals. All animal experiments performed for the present study complied with the National Institutes of Health guidelines for the handling of laboratory animals and were approved by the Ethics Committee of the Wuxi Medical College of Anhui Medical University (Wuxi, China). All experiments were conducted on healthy adult male C57BL/6J mice (22-25 g; age, 8-12-weeks; Anhui Medical University, Hefei, China). The mice were housed in animal care facilities with a 12-h light/dark cycle and had free access to food and water.

ICH animal model. The ICH mouse model was generated based on a previously described protocol involving autologous blood injection (32). Briefly, male C57BL6/J mice were anesthetized by intraperitoneal (i.p.) injection of $50 \mathrm{mg} / \mathrm{kg}$ pentobarbital sodium and placed in a prone position with a stereotactic head frame. The rectal temperature was kept at $37.0 \pm 0.5^{\circ} \mathrm{C}$ during the operation using a heating pad. An artificial tear ointment was used to protect the eyes from injury during surgery.
A midline scalp incision was made, and a cranial burr hole with a 1-mm diameter was made at the following coordinates relative to bregma: $0.2 \mathrm{~mm}$ posterior, $2.2 \mathrm{~mm}$ lateral to bregma, and $3.5 \mathrm{~mm}$ below the dura. A total of $30 \mu \mathrm{l}$ of autologous blood without anticoagulation was collected from the caudal artery and rapidly injected into the basal ganglia through the burr hole via the 26-gauge needle of a $10-\mu 1$ Hamilton syringe. First, $5 \mu \mathrm{l}$ of arterial blood was injected at a depth of $2.8 \mathrm{~mm}$ from the dura (injection speed, $3 \mu \mathrm{l} / \mathrm{min}$ ). Five minutes later, the other $25 \mu \mathrm{l}$ blood was injected at a depth of $3.5 \mathrm{~mm}$ (injection speed, $3 \mu \mathrm{l} / \mathrm{min}$ ). After the injection of autologous blood, the needle was kept in the brain for $10 \mathrm{~min}$ to prevent blood backflow along the needle tract. Finally, the hole was covered with medical bone wax. The animals in the Sham group received similar surgical procedures but were injected at the same site with an equal volume of sterile saline instead of blood. At $72 \mathrm{~h}$ following ICH, the mice were sacrificed with $100 \mathrm{mg} / \mathrm{kg}$ sodium pentobarbital via i.p. injection. Death was confirmed by observing respiration and by using the corneal reflection method. Brain tissue samples were collected after the mice were sacrificed. Fresh specimens were stored in liquid nitrogen $\left(-196^{\circ} \mathrm{C}\right)$ or $4 \%$ formalin-fixed $\left(4^{\circ} \mathrm{C}\right)$ for $\geq 48 \mathrm{~h}$.

Drug administration. Perampanel was purchased from Santa Cruz Biotechnology, Inc. (cat. no. sc-477647). The mice were orally administered with saline water or perampanel $(5 \mathrm{mg} / \mathrm{kg})$ for $24 \mathrm{~h}$ before ICH (Fig. 1A). HT22 cells (Procell Life Science \& Technology Co., Ltd.) were cultured in Dulbecco's modified Eagle's medium containing $10 \%$ fetal bovine serum and $1 \%$ penicillin/streptomycin and until $70 \%$ confluent at $37^{\circ} \mathrm{C}$ with $5 \% \mathrm{CO}_{2}$, then were treated with perampanel ( $2 \mathrm{mmol} / \mathrm{l})$ for $24 \mathrm{~h}$ prior to hemin insult (Fig. 1A). z-VAD-fmk (cat. no. 187389-52-2), 3-Methyladenine (3-MA; cat. no. 5142-23-4), and Necrostatin-1 (cat. no. 4311-88-0) were purchased from Selleck Chemicals.

Small interfering RNA (siRNA) treatment and transfection. Mice were anesthetized with pentobarbital sodium and placed on stereotactic apparatus. Then, a burr hole was made in the left hemisphere using the following coordinates: $0.2 \mathrm{~mm}$ posterior, $1 \mathrm{~mm}$ lateral, and $2.2 \mathrm{~mm}$ below the horizontal plane of the bregma. Then, $5 \mu \mathrm{l}(4 \mathrm{nM} / \mu \mathrm{l})$ siRNA molecules were injected into the left lateral ventricle at a rate of $0.5 \mu \mathrm{l} / \mathrm{min}$. To enhance the silencing effect, the injection was performed $48 \mathrm{~h}$ prior to ICH.

For in vitro cell transfection, Lipofectamine RNAiMax reagent (Invitrogen; Thermo Fisher Sceintific, Inc.) was used in Opti-MEM medium, according to the manufacturer's instructions. The transfection was performed at $37^{\circ} \mathrm{C}$ in a humidified incubator with $5 \% \mathrm{CO}_{2}$. Cells were transfected with siRNA at a concentration of $50 \mathrm{nM}$. Cells were incubated with siRNA and Lipofectamine ${ }^{\circledR} 2000$ for $6 \mathrm{~h}$ in transfection medium. Cells were harvested for further studies $72 \mathrm{~h}$ after the beginning of transfection. The following targeted and control siRNAs were synthesized by JiKai Biotechnology, Inc.: si-PTEN (Cy3-labeled siR-996) sense, 5'-GGUGUA UACAGGAACAAUATT-3' and antisense, 5'-UAUUGUUCC UGUAUACACCTT-3'; and negative control siRNA sense, 5'-UUCUCCGAACGUGUCACGUTT-3' and antisense, 5'-ACGUGACACGUUCGGAGAATT-3'. 
A
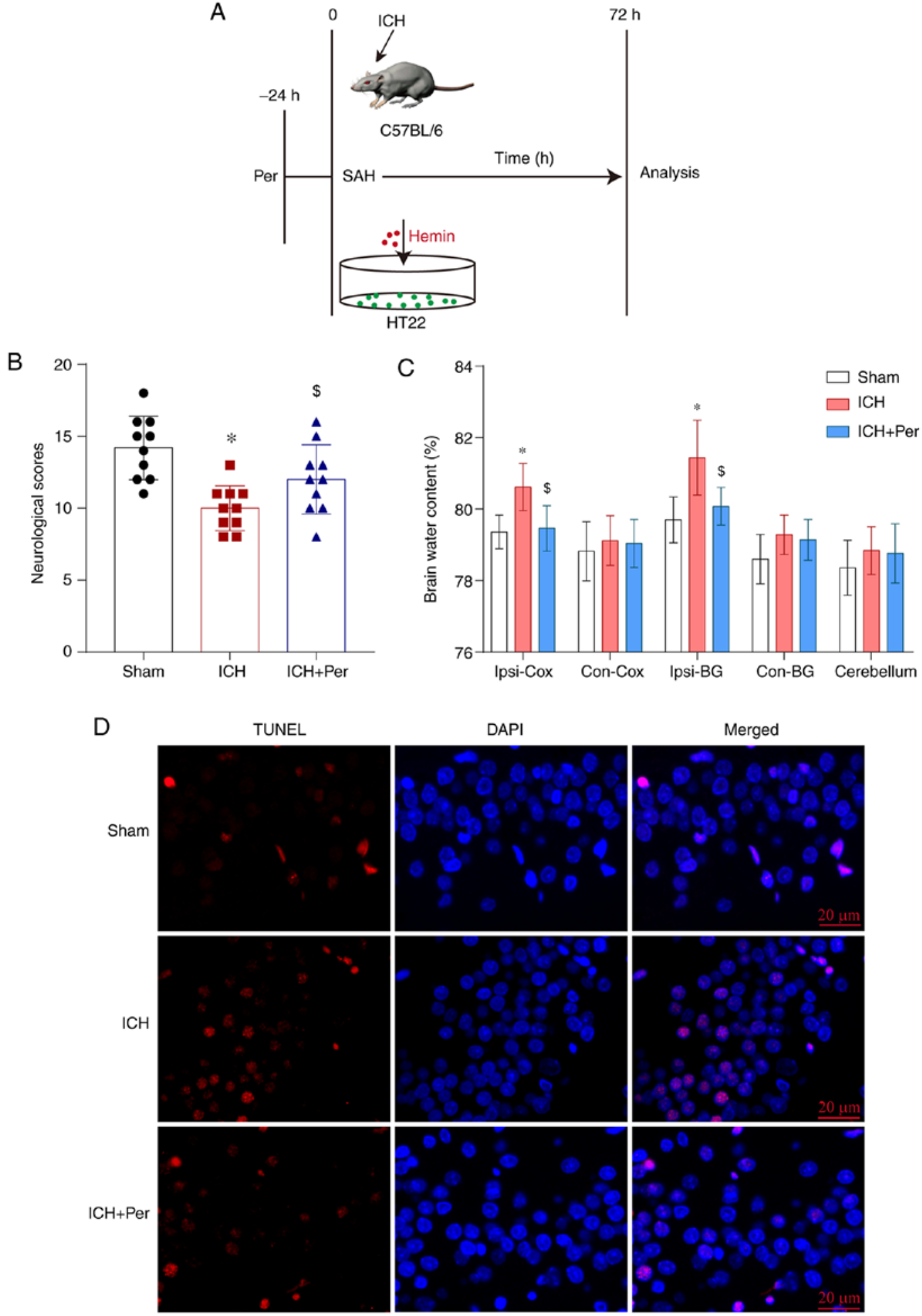

Figure 1. Perampanel alleviates early brain injury following ICH in vivo. (A) Diagram of the experimental design. (B) Neurological scores of the three experimental groups at $72 \mathrm{~h}$ after ICH $(\mathrm{n}=10)$. (C) Brain water content at $72 \mathrm{~h}$ after ICH $(\mathrm{n}=5)$. (D) Representative images of TUNEL assay staining in hippocampal sections at $72 \mathrm{~h}$ after ICH (n=5). Scale bar, $20 \mu \mathrm{m}$. Error bars indicate SEM. ${ }^{*} \mathrm{P}<0.01$ vs. sham group; ${ }^{\$} \mathrm{P}<0.05$ vs. ICH group. ICH, intracerebral hemorrhage; Per, perampanel; SAH, subarachnoid hemorrhage.

Neurobehavioral assessment. The severity of brain injury was determined by evaluating the neurological function of mice at $72 \mathrm{~h}$ after ICH, using our previously described neurological grading system (33). The scoring system consisted of six tests, and the specific standards are listed in the Table SI. The neurological scores ranged from 3 to 18 and included spontaneous activities (0-3), movement symmetry of all limbs (0-3), forelimb outstretching (0-3), body proprioception (1-3), response to vibrissae touch (1-3), and climbing (1-3). All mice from every group received a behavioral assessment, and a higher score represented better neurological function.

Brain water content measurement. The severity of brain edema was evaluated by measuring the brain water content using the 
standard wet-dry method, as previously reported $(15,33,34)$. The mice were sacrificed $72 \mathrm{~h}$ following ICH, and the entire brain was harvested and separated into the ipsilateral and contralateral cortex, ipsilateral and contralateral basal ganglia, and cerebellum (wet weight). Then, brain specimens from each group were dehydrated at $105^{\circ} \mathrm{C}$ for $24 \mathrm{~h}$ to acquire the dry weight. The percentage of brain water content was calculated using the following formula: (wet weight-dry weight)/wet weight $\times 100$.

TdT-mediated dUTP-biotin nick end labeling (TUNEL) assay. A TUNEL assay was conducted to assess neuronal death in the brain cortex and were fixed with $4 \%$ paraformaldehyde for $1 \mathrm{~h}$ at $25^{\circ} \mathrm{C}$. Paraffin-embedded sections $(10 \mu \mathrm{m})$ were cut from formalin-fixed tissue and stained with TUNEL staining. Specimens were examined under a light microscope (magnification, x200). TUNEL reaction mixture $(50 \mu \mathrm{l})$ was added to each sample, and the slides were incubated in a humidified dark chamber for $60 \mathrm{~min}$ at $37^{\circ} \mathrm{C}$. The slides were then incubated with DAPI for $5 \mathrm{~min}$ at room temperature in the dark to stain the nuclei, followed by imaging with a fluorescence microscope. The procedure was performed according to the manufacturer's instructions with a TUNEL staining kit. A negative control (without the TUNEL reaction mixture) was used. The apoptotic index (\%) was the ratio of the number of TUNEL-positive cells/total number of cells x100. The cell count was confirmed in four randomly selected high-power fields, and the data obtained from each field were averaged.

Cytokine measurements of ipsilateral cortex tissue. The levels of IL-1 $\beta$ (cat. no. ab197742; Abcam), IL-6 (cat. no. ab222503; Abcam), TNF- $\alpha$ (cat. no. ab208348; Abcam), and NF- $\kappa B$ (cat. no. ab176663; Abcam) were measured by ELISA, according to the manufacturer's instructions.

In vitro ICH model in HT22 cells. The hemin-induced ICH method was used to construct the in vitro cell ICH model as previously described (35). For in vitro ICH experiments, cell death was induced in hippocampal HT22 cells by treatment with hemin (dose-response, 20-140 $\mathrm{mM}$ for $48 \mathrm{~h}$; Sigma-Aldrich; Merck KGaA; cat. no. H9039). In the present study, cells were treated with $100 \mathrm{mM}$ hemin (median lethal dose) in the presence of sodium selenite (Sigma-Aldrich; Merck $\mathrm{KGaA}$ ) dissolved in $\mathrm{ddH}_{2} \mathrm{O}$. Hemin was prepared and diluted to a final concentration of $80 \mathrm{mM}$ with culture medium and sterilized by filtration through a $0.22-\mu \mathrm{m}$ sterile filter. Cell viability was analyzed $72 \mathrm{~h}$ after treatment. Cells were then washed in prewarmed PBS $\left(37^{\circ} \mathrm{C}\right)$ and assessed by an MTT assay as per the manufacturer's instructions (Promega Corporation). As determined in a prior study (15), neurons were stimulated with $80 \mathrm{mM}$ hemin for $72 \mathrm{~h}$ to mimic intracranial hemorrhage conditions.

MTT assay for cell viability. Cell viability was assessed with a 3-(4,5-dimethylthiazol-2-yl)-2,5-diphenyl tetrazolium bromide (MTT) assay and dead/live assay. For the MTT assay, HT22 cells were seeded into 96-well plates, then $20 \mu \mathrm{l}$ MTT (Sigma-Aldrich; Merck KGaA) was added to each well and the plate was incubated at $37^{\circ} \mathrm{C}$ for $4 \mathrm{~h}$. The culture medium was removed, and formazan crystals were lysed in
$150 \mu 1$ dimethylsulfoxide (DMSO) by gently shaking the plate. Subsequently, the optical density was determined in a microplate reader (Bio-Rad Laboratories, Inc.) at $490 \mathrm{~nm}$.

Dead/live assay. For the dead/live assay, HT22 cells were washed twice and resuspended in PBS, and then samples were exposed to propidium iodide (PI; $4 \mu \mathrm{M})$ and calcein-AM $(3 \mu \mathrm{M})$ for $20 \mathrm{~min}$ in the dark at room temperature. Cells were washed and resuspended in PBS and analyzed under a fluorescence microscope system (DMIL 4000B; Leica Microsystems $\mathrm{GmbH}$ ). Bound PI produces red fluorescence and indicates dead cells, whereas calcein-AM produces green fluorescence and indicates live cells. Cell viability was expressed as a percentage relative to the values obtained from the control cultures. All experiments were independently repeated in triplicate.

Reverse transcription-quantitative PCR (RT- $q P C R)$. RT-qPCR analysis was performed as indicated previously (36). Total RNA was extracted from either cell cultures or hippocampal brain samples using TRIzol reagent (Thermo Fisher Scientific, Inc.), according to the manufacturer's instructions. Then, RNA was reverse transcribed to cDNA using the RevertAid First Strand cDNA Synthesis kit (cat. no. K1622; Thermo Fisher Scientific Inc.). Receptor interacting serine/threonine kinase (RIP) 1, RIP3, mixed lineage kinase domain like pseudokinase (MLKL), and PTEN mRNA expression levels in each sample were measured by qPCR using SYBR Green Master Mix (Toyobo Life Science). GAPDH was used as an internal control. The qPCR thermocycling conditions were as follows: $45^{\circ} \mathrm{C}$ for $2 \mathrm{~min}$ and $95^{\circ} \mathrm{C}$ for $10 \mathrm{~min}$, followed by 40 cycles of denaturation at $95^{\circ} \mathrm{C}$ for $15 \mathrm{sec}$, annealing at $60^{\circ} \mathrm{C}$ for $1 \mathrm{~min}$, and extension at $72^{\circ} \mathrm{C}$ for $1 \mathrm{~min}$. The $2^{-\Delta \Delta \mathrm{Cq}}$ method was used to assess the relative RNA expression levels (37). All samples were analyzed in triplicate. The primers used are listed in Table SII.

Western blot analysis. Western blot analysis was performed as indicated previously (34). Briefly, cerebral cortex samples or HT22 cell homogenates were collected using RIPA lysis buffer (Beyotime Institute of Biotechnology) containing protease inhibitor cocktail (Sigma-Aldrich; Merck KGaA), dissolved, and separated by $10 \%$ SDS-PAGE. A BCA Protein Assay kit (Beyotime Institute of Biotechnology) was used to measure protein concentrations by the bicinchoninic acid method. Then, protein samples (30 $\mu \mathrm{g} /$ lane) were transferred onto immobilon nitrocellulose membranes. The membranes were blocked at room temperature for $1 \mathrm{~h}$ with $5 \%$ non-fat milk. The membranes were then incubated with the following primary antibodies overnight at $4^{\circ} \mathrm{C}$ : Rabbit anti- $\beta$-actin $(1: 1,000$; rabbit polyclonal; Abcam; cat. no. ab8227), rabbit anti-RIP1 (1:1,000; rabbit polyclonal; Abcam; cat. no. ab106393), rabbit anti-RIP3 (1:1,000; rabbit polyclonal; Abcam; cat. no. ab62344), rabbit anti-MLKL (1:1,000; rabbit monoclonal; Abcam; cat. no. ab196436), and rabbit anti-PTEN (1:1,000; rabbit monoclonal; Abcam; cat. no. ab267787). After washing the membranes with TBST three times, HRP-conjugated goat anti-rabbit IgG or goat anti-mouse IgG secondary antibodies (1:2,000; cat. no. 7074s; Cell Signaling Technology, Inc.) were applied, and the membranes were incubated with the secondary 
A
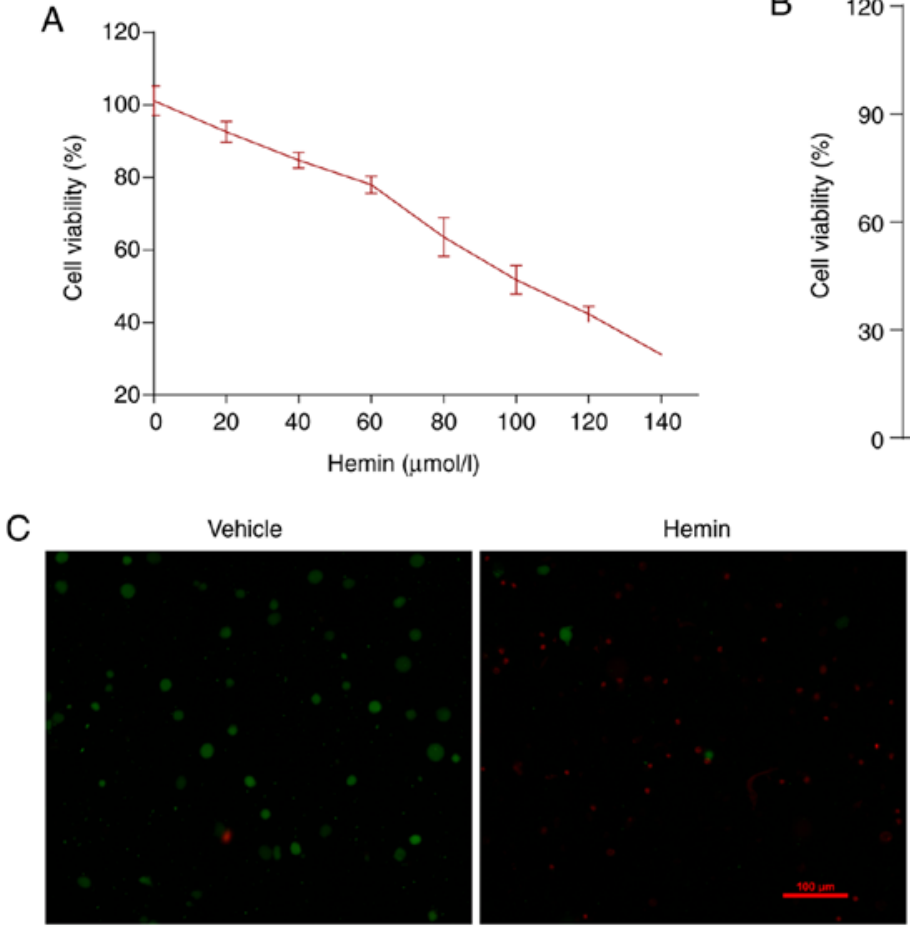

B
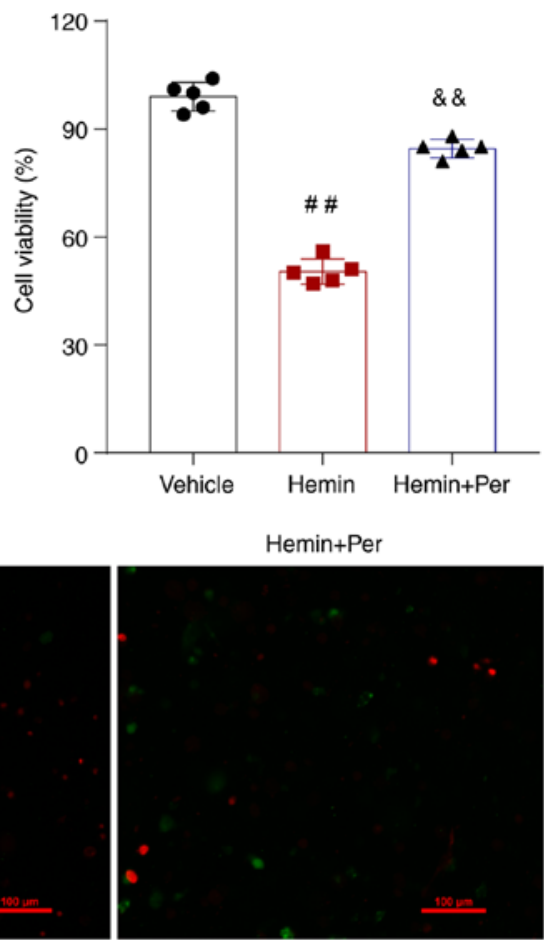

Figure 2. Perampanel relieves hemin-induced HT22 neuronal injury in vitro. (A) MTT assay of HT22 cells treated with $0-140 \mu \mathrm{M}$ hemin. $100 \mu \mathrm{M}$ hemin was used as the test dosage. (B) MTT assay of HT22 cells treated with hemin alone or hemin and perampanel $(\mathrm{n}=5)$. (C) Representative images of live ( green)/dead (red) staining assay of HT-22 neurons exposed to hemin $(100 \mu \mathrm{M}, 72 \mathrm{~h})$ in the presence and absence of perampanel (n=5). Scale bar=100 $\mu \mathrm{m}$. Error bars indicate SEM. ${ }^{\# \#} \mathrm{P}<0.01$ vs. vehicle group; ${ }^{\&} \mathrm{P}<0.01$ vs. hemin group. Per, perampanel.

antibodies at room temperature for $1.5 \mathrm{~h}$. The protein bands were detected using a Bio-Rad imaging system (Bio-Rad Laboratories, Inc.) and quantified with ImageJ (version 1.52; National Institutes of Health).

Statistical analysis. All experiments were repeated at least three times, and the data are expressed as the means \pm SEM. SPSS 14.0 (SPSS, Inc.) and GraphPad Prism 6 (GraphPad Software, Inc.) were used for the statistical analyses. Student's t-test was used if two groups were compared, and one-way analysis of variance followed by Bonferroni's post hoc test was used if two independent variables were compared. For nonnormally distributed data and/or nonhomogeneous variance, the Kruskal-Wallis test was used followed by Dunn's post hoc test. $\mathrm{P}<0.05$ was considered to indicate a statistically significant difference.

\section{Results}

Perampanel alleviates early brain injury following ICH in vivo. To explore the neuroprotective effects of perampanel, the autologous blood injection method was used to construct an ICH model in vivo (Fig. 1A). To investigate early brain injury following $\mathrm{ICH}$, the present study determined the levels of brain water content, neurological scores, and apoptosis rates by TUNEL assay at $72 \mathrm{~h}$ after $\mathrm{ICH}$. The results demonstrated that neurological scores were decreased significantly following $\mathrm{ICH}$, and that perampanel administration significantly ameliorated this effect $(\mathrm{P}<0.05$; Fig. 1B). In addition, the brain water content in the ipsilateral cortex and basal ganglia was significantly increased following ICH $(\mathrm{P}<0.05)$, and perampanel treatment attenuated this effect $(\mathrm{P}<0.05)$ (Fig. 1C). There was no significant difference in the brain water content among the three experimental groups in the contralateral cortex, basal ganglia, or cerebellum (Fig. 1C). To investigate hippocampal neuron death following ICH and the neuroprotective effects of perampanel, the present study used a TUNEL assay to quantify the level of cell death in treated and untreated ICH mice at $72 \mathrm{~h}$ after model construction. The present results indicated increased hippocampal neuron death following ICH, which was markedly decreased by perampanel administration (Fig. 1D). Thus, the present data confirmed the neuroprotective effects of perampanel in $\mathrm{ICH}$.

Perampanel relieves hemin-induced HT22 neuronal injury in vitro. To assess the neuroprotective effect of perampanel in vitro, a hemin-induced method was used to construct an ICH model in cultured cells (Fig. 1A). Then, an MTT assay was used to evaluate HT22 neuron viability following hemin-induced ICH. The results demonstrated that hemin administration induced HT22 neuron death in a dose-dependent manner (Fig. 2A). Of note, the hemin-induced neuronal cell death was significantly attenuated by perampanel at $72 \mathrm{~h}$ (Fig. 2B). A dead/live immunofluorescent staining assay was also used to detect neuronal death at $72 \mathrm{~h}$. The results indicated that neuronal death increased following hemin-induced $\mathrm{ICH}$, and that perampanel treatment relieved hemin-induced neuronal injury in vitro (Fig. 2C).

Perampanel relieves neuroinflammation following ICH. Neuroinflammation serves a key role in the progression of ICH-induced brain injury, and a previous study demonstrated 

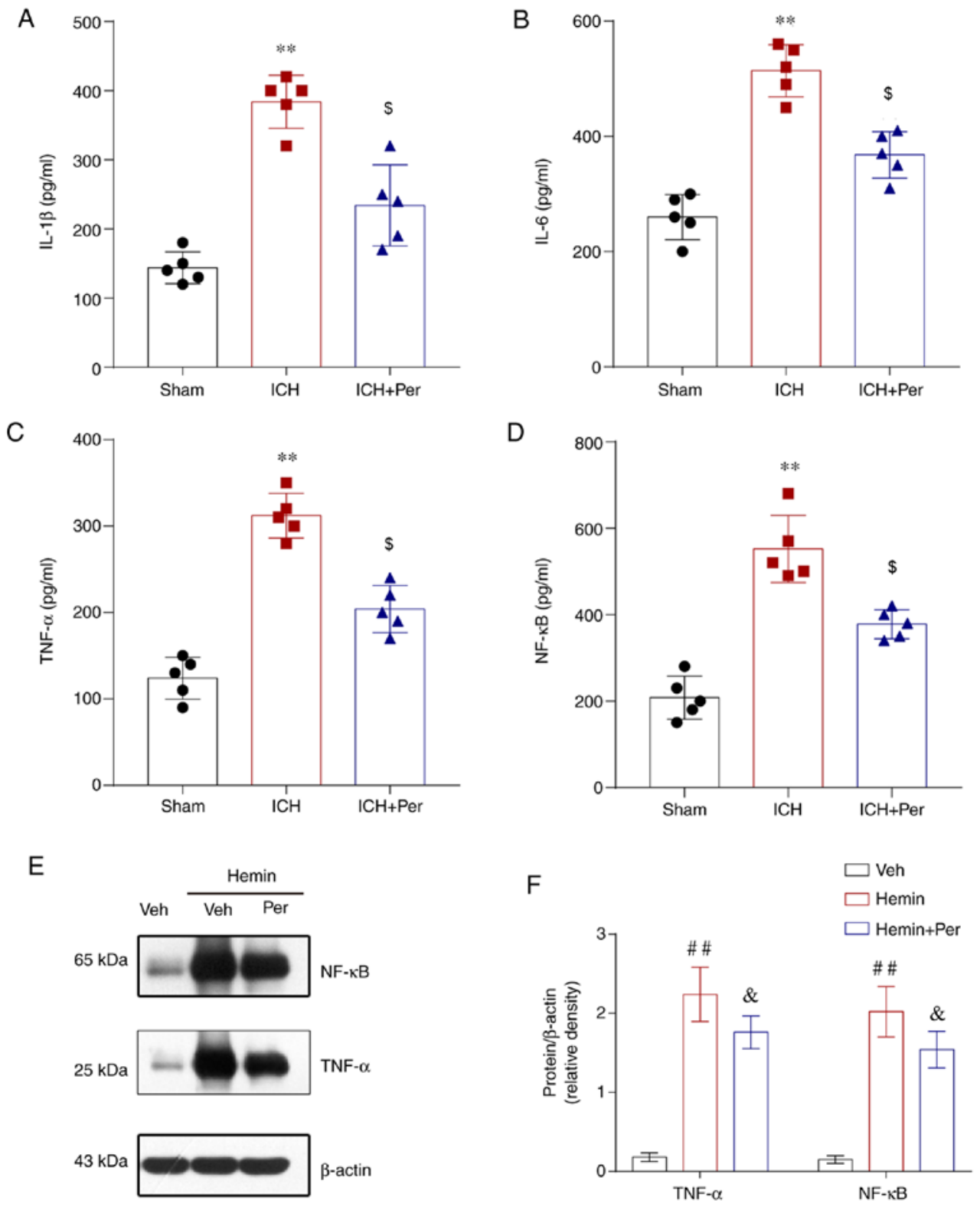

Figure 3. Perampanel relieves neuroinflammation following ICH. (A) Level of IL-1 $\beta$, (B) IL-6, (C) TNF- $\alpha$, and (D) NF- $\kappa$ B were measured after ICH in ipsilateral cortex tissue by ELISA. (E) Representative blots and (F) quantification of protein expression levels of TNF- $\alpha$ and NF- $\kappa \mathrm{B}$ after hemin-induced ICH in vitro by western blotting. Error bars indicate SEM. ${ }^{* *} \mathrm{P}<0.01$ vs. sham group; ${ }^{\circ} \mathrm{P}<0.05$ vs. ICH group; ${ }^{\# \#} \mathrm{P}<0.01$ vs. vehicle group; ${ }^{\circledR} \mathrm{P}<0.05$ vs. hemin group. ICH, intracerebral hemorrhage; Per, perampanel; Veh, vehicle.

that the neuroprotective effect of perampanel after traumatic brain injury (TBI) may be associated with the anti-inflammatory response (27). Therefore, the present study measured the levels of inflammatory cytokines IL- $1 \beta$, IL- 6 , TNF- $\alpha$, and NF- $\kappa \mathrm{B}$ by ELISA. The results showed that the levels of IL-1 $\beta$, IL-6, TNF- $\alpha$, and NF- $\kappa$ B in the ipsilateral cortex were increased significantly following ICH and this increase was attenuated by perampanel treatment in vivo (Fig. 3A-D). Furtermore, the protein expression levels of TNF- $\alpha$ and $\mathrm{NF}-\mathrm{kB}$ were measured by western blot analysis in vitro, and the results confirmed that perampanel treatment significantly alleviated the hemin-induced TNF- $\alpha$ and NF- $\kappa B$ upregulation in HT22 cells (Fig. 3E-F).

Perampanel suppresses necroptosis following ICH. Previous studies have indicated that perampanel can improve brain injury outcomes following traumatic brain injury by regulating neuronal necroptosis $(27,28)$. Therefore, the present study also investigated whether perampanel improves brain injury after ICH via the necroptosis pathway. First, the mRNA expression levels of the necroptosis-related genes RIP1, RIP3, and MLKL in the cerebral cortex were determined by RT-qPCR. As expected, the mRNA expression levels of RIP1, RIP3, and MLKL mRNA increased after ICH and decreased after perampanel treatment (Fig. 4A-C). The protein expression levels of RIP1, RIP3, and MLKL in the cerebral cortex were also measured by western blot analysis. The results were similar to the mRNA analysis results (Fig. 4D-G). The specific role of necroptosis, a process that is different from apoptosis and autophagy, was explored next in hemin-induced ICH in vitro. The results demonstrated that inhibitors of caspase-dependent apoptosis (z-VAD-fmk) and autophagy (3-MA) did not affect 
A

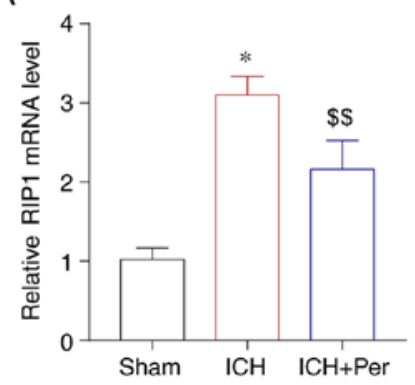

D

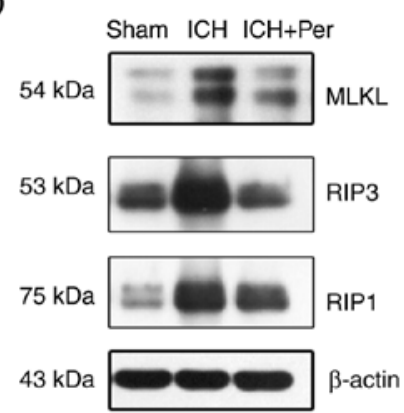

G

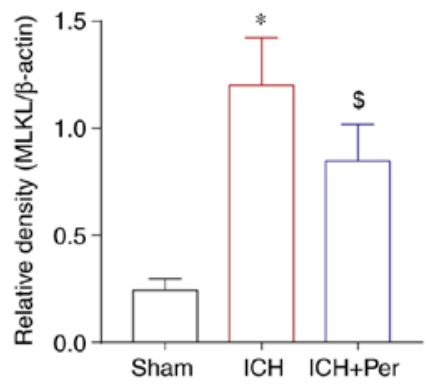

B

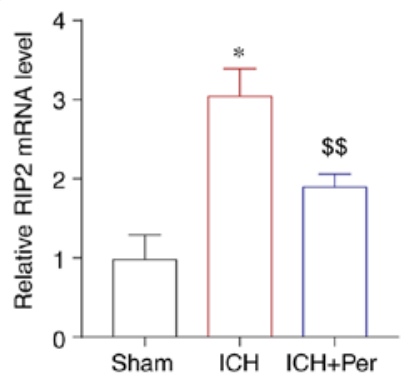

E

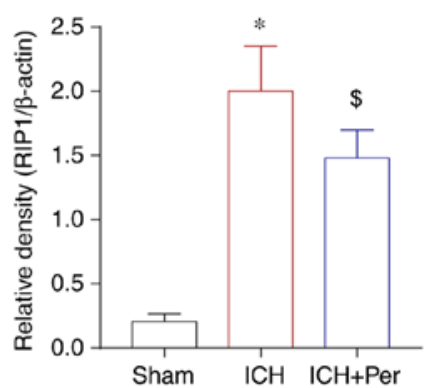

C

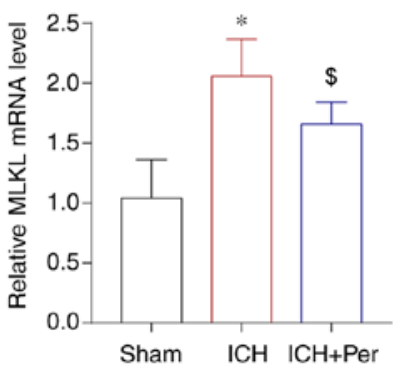

F

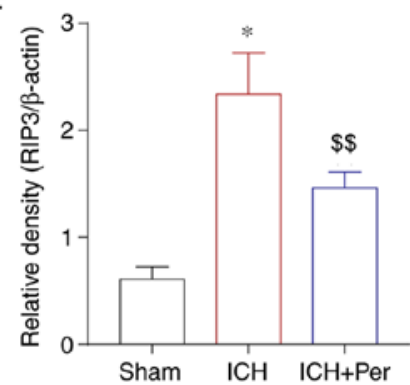

$\mathrm{H}$

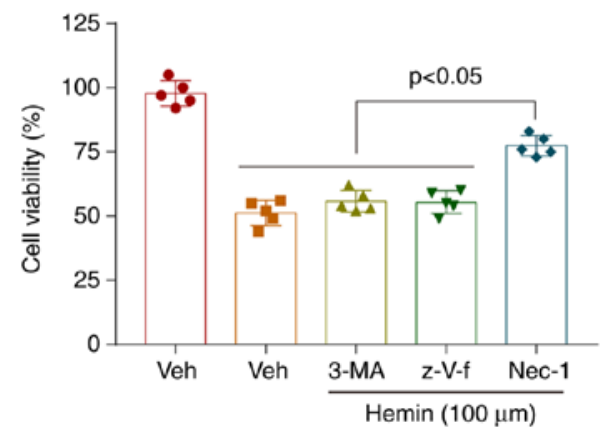

Figure 4. Perampanel suppresses necroptosis following ICH. (A) mRNA expression levels of RIP1, (B) RIP3, and (C) MLKL were determined after ICH by reverse transcription-quantitative PCR analysis. (D) Representative blots and (E-G) quantification of RIP1, RIP3, and MLKL protein expression levels after $\mathrm{ICH}$, as determined by western blotting. (H) MTT assay of HT22 cells treated in vitro with hemin in the absence or presence of inhibitors of caspase-dependent apoptosis (z-VAD-fmk), autophagy (3-MA), or necroptosis (Nec-1). Error bars indicate SEM ( $\mathrm{n}=5$ ). ${ }^{*} \mathrm{P}<0.01$ vs. sham group; ${ }^{\$} \mathrm{P}<0.05$ and ${ }^{\$} \mathrm{P}<0.01$ vs. $\mathrm{ICH}$ group. ICH, intracerebral hemorrhage; RIP, receptor interacting serine/threonine kinase; MLKL, mixed lineage kinase domain like pseudokinase; Nec-1, necrostatin-1.

hemin-induced neuronal injury in vitro, while an inhibitor of necroptosis-dependent apoptosis (necrostatin-1) significantly attenuated neuronal death (Fig. 4H).

The neuroprotective effect of perampanel is mediated via the PTEN signaling pathway. As Kim et al (38) reported that AMPAR-mediated spontaneous seizure activity may abolish PTEN activity in the epileptic hippocampus, PTEN may be required for the antiepileptic effects of AMPAR antagonists (25). Therefore, the present study explored whether the antinecroptotic role of perampanel may occur via the PTEN signaling pathway. First, the mRNA expression levels of PTEN were measured after hemin-induced ICH and perampanel treatment in vitro. The results demonstrated that PTEN mRNA expression was reduced after $\mathrm{ICH}$, and this reduction was alleviated by perampanel treatment (Fig. 5A). Similar results were observed at the protein level, as determined by western blot analysis (Fig. 5B and C).

Next, transfection with PTEN-targeting siRNA was performed to silence the expression of PTEN in the hemin-induced ICH model in vitro. RT-qPCR was used to confirm that the transfections were successful and PTEN expression was efficiently silenced (Fig. S1). Following PTEN knockdown, the hemin-induced neuronal death was not improved after perampanel treatment (Fig. 5D and E). Therefore, the neuroprotective effect of perampanel was reversed by knockdown of PTEN in the ICH in vitro model.

Perampanel alleviates PTEN-dependent brain injury in vivo. The in vitro results demonstrated that hemin-induced $\mathrm{ICH}$ decreased the expression of PTEN, perampanel treatment increased PTEN expression, and PTEN knockdown blocked the neuroprotective effects of perampanel. To further investigate the role of PTEN in the in vivo ICH model, si-PTEN was infused into the left lateral ventricle of mice to downregulate the expression of PTEN. The results showed that the behavioral score and ipsilateral basal ganglia brain edema were improved by perampanel treatment, but this effect was partially blocked by PTEN knockdown (Fig. 6A and B). The expression levels of the necroptosis-related proteins RIP1 and 
A

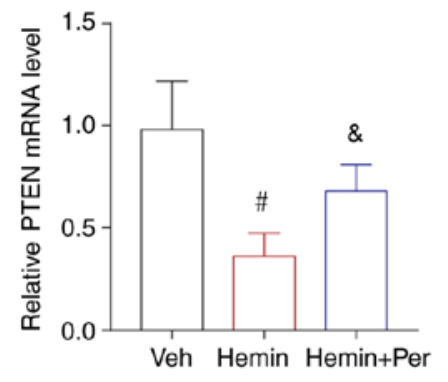

D

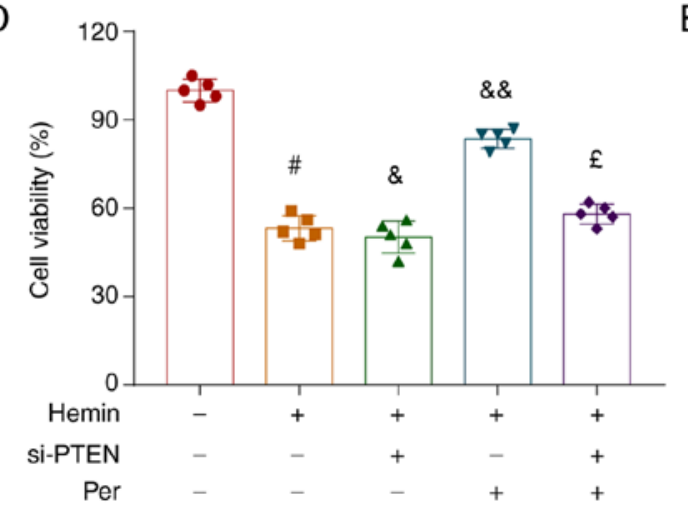

B

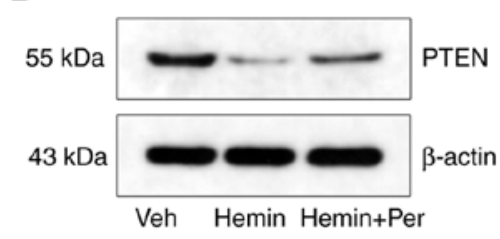

C

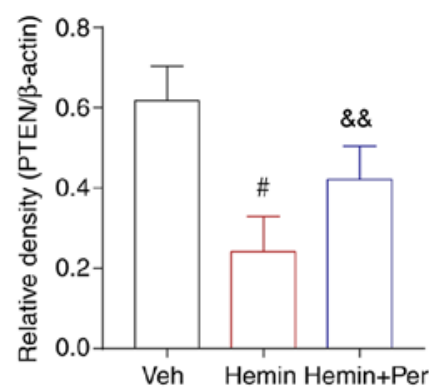

E

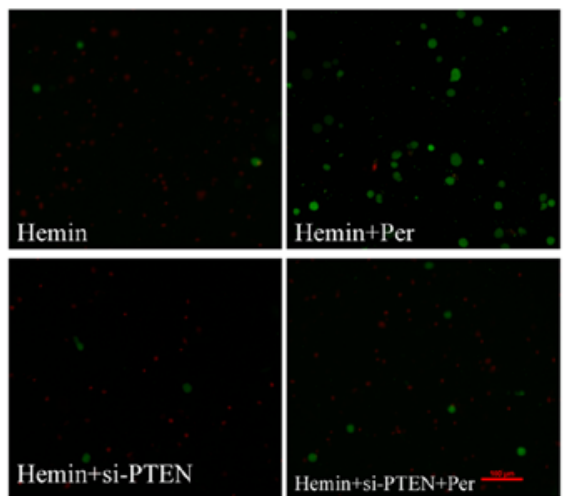

Figure 5. Antinecroptosis effects of perampanel are mediated via the PTEN signaling pathway. (A) mRNA expression levels of PTEN in HT22 cells treated with hemin in the absence or presence of perampanel. (B) Representative blots and (C) quantification of protein expression levels of PTEN. (D) MTT assay of HT22 cells treated with hemin, perampanel and/or si-PTEN. (E) Representative images of live (green)/dead (red) staining assays of HT22 cells treated with hemin, perampanel and/or si-PTEN. Scale bar $=100 \mu \mathrm{m}$. Error bars indicate SEM $(\mathrm{n}=5) .{ }^{\sharp} \mathrm{P}<0.05$ vs. vehicle group; ${ }^{\star} \mathrm{P}<0.05$ and \&\& $\mathrm{P}<0.01$ vs. hemin group; ${ }^{\mathrm{f}} \mathrm{P}<0.05$ vs. hemin +Per group. si, small interfering; Per, perampanel; Veh, vehicle.

RIP3 in the ipsilateral cortex tissue were also decreased after perampanel treatment, and this effect was reduced following PTEN knockdown (Fig. 6C-E). Finally, TUNEL staining of brain sections was performed (Fig. 6F), and the results showed that the antinecroptotic role of perampanel was partially inhibited by PTEN knockdown.

\section{Discussion}

The present study evaluated the therapeutic potential of perampanel in alleviating early brain injury in an in vivo ICH mouse model and an in vitro hemin-induced ICH cell culture model. The current results demonstrated that perampanel acted as a neuroprotective agent that attenuated early brain injury and neuronal death following ICH. In specific, it was found that: i) Perampanel improved neurological dysfunction following $\mathrm{ICH}$; ii) perampanel alleviated brain damage in a mouse $\mathrm{ICH}$ model and in a hemin-induced HT22 cell neuronal injury model; iii) perampanel relieved neuroinflammation after ICH and decreased brain inflammatory damage; iv) perampanel prevented necroptosis after ICH and alleviated neuronal death; and v) the antineuroinflammatory and antinecroptotic roles of perampanel may be mediated by the PTEN pathway.

Perampanel, an orally active, noncompetitive, selective AMPAR antagonist, has been widely used for the treatment of epilepsy (23). Previous studies have revealed that AMPAR antagonists are important potential neuroprotective agents in preclinical models of ischemic stroke (39), spinal cord injury (40), and traumatic brain injury (27). However, while these early studies revealed that AMPAR antagonists could minimize brain injury and neuronal death following $\mathrm{ICH}$, the potential molecular mechanisms and consequent effects were not explored. Chen et al (27) first reported that the AMPAR antagonist perampanel could alleviate TBI-induced neuronal injury and neurological dysfunction by suppressing the expression of proinflammatory cytokines and increasing the levels of anti-inflammatory cytokines. The underlying mechanisms may be related to antioxidative and anti-inflammatory activities. Aida et al (41) also demonstrated that pre- or postinjury administration of perampanel could reduce impairments in learning and memory, and impairments in reward-seeking behavior, by inhibiting hippocampal cell apoptosis. In brain hemorrhage, Dohare et al (25) first found that AMPA-specific inhibition by FDA-approved perampanel can decrease oligodendrocyte precursor cell injury, rebuild myelination, and improve neurologic recovery in rabbits with $\mathrm{ICH}$. In addition to reporting mechanisms of apoptosis and oxidative and inflammatory activity, Chen et al (28) first indicated that necroptosis had a critical role in neuronal death following traumatic neuronal injury in an in vitro model, and that perampanel could regulate necroptosis via the AKT/GSK3 $\beta$ signaling pathway.

Necroptosis is a newly discovered pathway of regulated necrosis, a caspase-independent programmed cell death mechanism that requires the proteins RIP3 and MLKL and is induced by death receptors (42). Increasing evidence suggests that necroptosis serves a critical role in central nervous system diseases, including traumatic brain injury $(28,43,44)$, ICH $(45,46)$, ischemic stroke (47), amyotrophic lateral sclerosis, Parkinson's disease, and Alzheimer's disease (48). The 
A

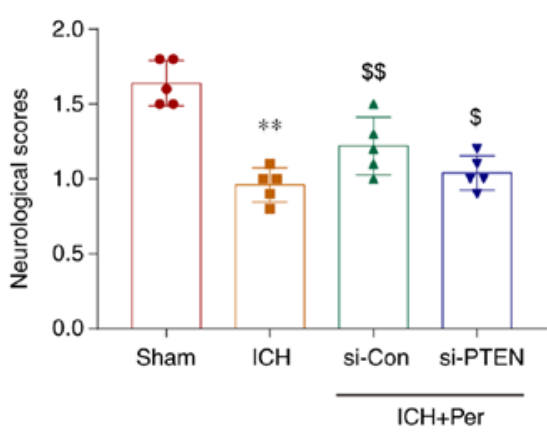

B

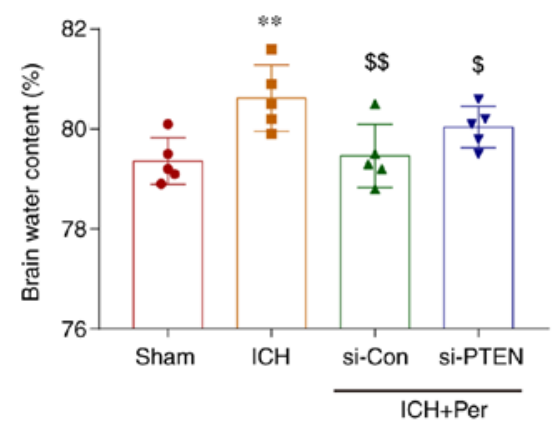

C

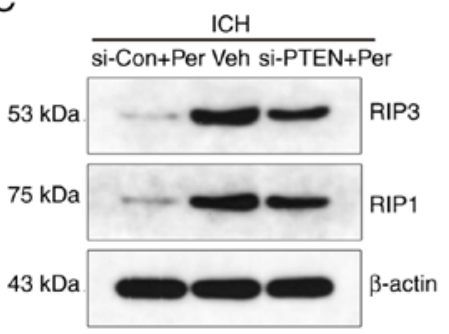

D

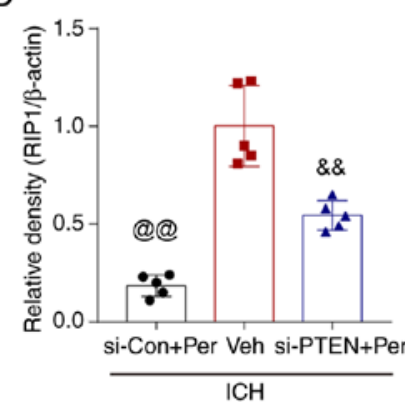

E

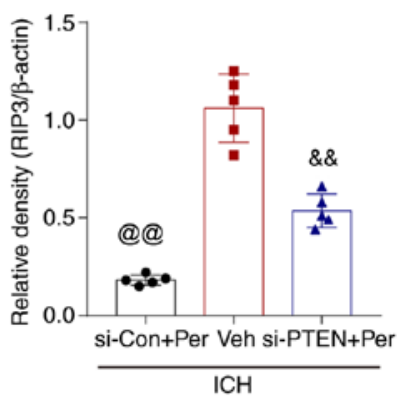

F

TUNEL
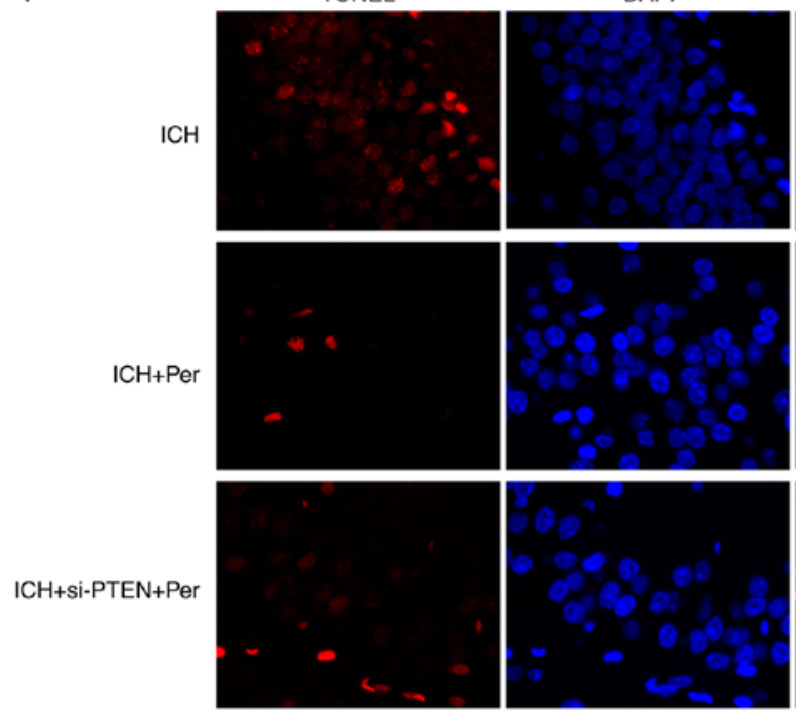
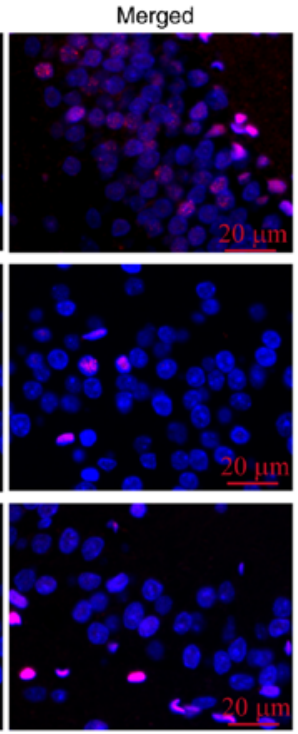

Figure 6. Perampanel alleviates PTEN-dependent brain injury in vivo. si-PTEN was infused in the brain of mice $48 \mathrm{~h}$ prior to ICH establishment and permpanel treatment. (A) Neurological scores at $72 \mathrm{~h}$ after ICH. (B) Brain water content. (C) Representative blots and (D and E) quantification of RIP1 and RIP3 protein expression levels after ICH, as determined by western blotting. (F) Infusion with si-PTEN increased neuronal death after ICH, as determined by TUNEL staining. Scale bar $=100 \mu \mathrm{m}$. Error bars indicate $\mathrm{SEM}(\mathrm{n}=5) .{ }^{* *} \mathrm{P}<0.01$ vs. sham group; ${ }^{\$} \mathrm{P}<0.05$ and ${ }^{\$ \$} \mathrm{P}<0.01 \mathrm{vs}$. ICH group; ${ }^{\circledR} \mathrm{P}<0.01$ vs. ICH +Veh group; ${ }^{\&} \mathrm{P}<0.01$ vs. ICH+si-Con+Per group. si, small interfering; ICH, intracerebral hemorrhage; RIP, receptor interacting serine/threonine kinase; Con, control; Per, perampanel; Veh, vehicle.

most upstream signaling activity required for the induction of necroptosis is the activation of a TNF ligand family member (such as RIP1 and MLKL); RIPK1 activation leads to necroptosis through the formation of a RIP1/RIP3/MLKL complex (49). The present study revealed that the protein and mRNA expression levels of RIP1, RIP3, and MLKL were elevated $72 \mathrm{~h}$ after the ICH procedure, and perampanel decreased the expression of RIP1, RIP3, and MLKL. Necrostatin-1 is a specific inhibitor of RIP1 that prevents necroptosis and ameliorates cell death, brain edema, and neuroinflammation and improves behavioral scores following ischemic brain injury and traumatic brain injury $(28,45,47)$. Furthermore, Xu et al (50) reported that necrostatin-1 could prevent glutamate-induced glutathione depletion and decrease caspase-independent cell death in HT22 cells. The present results also revealed that necrostatin- 1 significantly decreased neuronal death after hemin-induced HT22 neuronal injury.

Although the results of many studies have confirmed that necroptosis and RIP1 are involved in multiple central nervous system diseases, the regulatory mechanisms and molecular networks of necroptosis remain unclear. Chen et al (43) reported that activity regulated cytoskeleton associated protein (Arc) 
silencing aggravated neuronal injury via the metabotropic glutamate receptor 1-mediated endoplasmic reticulum stress pathway and RIP1-dependent necroptosis. Recent studies have revealed that iron overload can induce necroptosis of osteoblastic cells in vitro partly through the RIP1/RIP3/MLKL pathway, and reactive oxygen species (ROS) have an important role in regulating necroptosis (51-53). The present study demonstrated that necroptosis lead to neuronal death after ICH and hemin-induced $\mathrm{ICH}$, that neuronal death was inhibited by perampanel treatment, and that the neuroprotectice effects of perampanel were dependent on the PTEN pathway. Hence, the current results indicated that perampanel could reduce neuronal death and brain injury by protecting against neural necroptosis through the PTEN pathway. Wang et al (29) also reported that Chlorpyrifos induced fish liver cell necroptosis by regulating the ROS/PTEN/PI3K/AKT axis. The role of PTEN in the necroptosis molecular regulatory network was also confirmed in human seminoma and prostate cancer cells $(30,54)$. Previous studies have revealed that the expression levels of PTEN are high in mouse brain neurons and can regulate survival and death, and that PTEN inhibition has a vital role in neuroprotection following ICH $(55,56)$. Additionally, the PTEN pathway is involved in regulating neuroinflammation and mediating microglial and astrocyte activation and neuronal degeneration $(57,58)$. Together, the present findings indicated that the antinecroptosis and antineuroinflammation effects of perampanel occur at least in part through the regulation of the PTEN pathway after ICH. However, further studies are needed to fully elucidate the specific underlying regulatory mechanisms of necroptosis in ICH-induced early brain injury.

In summary, the present study demonstrated that the noncompetitive AMPAR antagonist perampanel exerted potent neuroprotective effects in early brain injury and protected against ICH-induced neuronal death in both in vivo and in vitro models. Perampanel alleviated brain injury and inhibited neuroinflammation and necroptosis. The neuroprotective effects of perampanel were found to be mediated by PTEN. The present findings indicated that perampanel is a neuroprotective agent that might improve the clinical management of early brain injury after ICH.

\section{Acknowledgements}

The authors would like to thank Dr Tao Chen (904th Hospital of Joint Logistic Support Force of PLA, Wuxi, China) for providing technical and theoretical assistance.

\section{Funding}

No funding was received.

\section{Availability of data and materials}

The datasets used and/or analyzed during the current study are available from the corresponding author on reasonable request.

\section{Authors' contributions}

LY performed the experiments and wrote the manuscript. $\mathrm{LY}, \mathrm{YW}$ and $\mathrm{CZ}$ assisted in performing the experiments and processed the figures. $\mathrm{HC}$ designed the study and revised the manuscript. LY and HC confirm the authenticity of all the raw data. All authors read and approved the final manuscript.

\section{Ethics approval and consent to participate}

All protocols involving animals were approved by the Ethics Committee of the Wuxi Medical College of Anhui Medical University (Wuxi, China; approval no. YXLL-2020-009).

\section{Patient consent for publication}

Not applicable.

\section{Competing interests}

The authors declare that they have no competing interests.

\section{References}

1. Zhang Y, Zhang X, Wei Q, Leng S, Li C, Han B, Bai Y, Zhang H and Yao H: Activation of Sigma-1 receptor enhanced pericyte survival via the interplay between apoptosis and autophagy: Implications for blood-brain barrier integrity in stroke. Transl Stroke Res 11: 267-287, 2020.

2. Zhang Z, Cho S, Rehni AK, Quero HN, Dave KR and Zhao W: Automated assessment of hematoma volume of rodents subjected to experimental intracerebral hemorrhagic stroke by bayes segmentation approach. Transl Stroke Res 11: 789-798, 2020.

3. Gross BA, Jankowitz BT and Friedlander RM: Cerebral intraparenchymal hemorrhage: A Review. JAMA 321: 1295-1303, 2019.

4. Wu X, Luo J, Liu H, Cui W, Guo K, Zhao L, Bai H, Guo W, Guo H, Feng D and Qu Y: Recombinant adiponectin peptide ameliorates brain injury following intracerebral hemorrhage by suppressing astrocyte-derived inflammation via the inhibition of Drp1-mediated mitochondrial fission. Transl Stroke Res 11: 924-939, 2020.

5. Hanley DF, Thompson RE, Rosenblum M, Yenokyan G, Lane K, McBee N, Mayo SW, Bistran-Hall AJ, Gandhi D, Mould WA, et al: Efficacy and safety of minimally invasive surgery with thrombolysis in intracerebral haemorrhage evacuation (MISTIE III): A randomised, controlled, open-label, blinded endpoint phase 3 trial. Lancet 393: 1021-1032, 2019.

6. Chen J, Wang Y, Wu J, Yang J, Li M and Chen Q: The potential value of targeting ferroptosis in early brain injury after acute CNS disease. Front Mol Neurosci 13: 110, 2020.

7. Adeoye $\mathrm{O}$ and Broderick JP: Advances in the management of intracerebral hemorrhage. Nat Rev Neurol 6: 593-601, 2010.

8. Mendelow AD, Gregson BA, Rowan EN, Murray GD, Gholkar A and Mitchell PM: Early surgery versus initial conservative treatment in patients with spontaneous supratentorial lobar intracerebral haematomas (STICH II): A randomised trial. Lancet 382: 397-408, 2013.

9. Zhou Y, Wang Y, Wang J, Anne Stetler R and Yang QW: Inflammation in intracerebral hemorrhage: From mechanisms to clinical translation. Prog Neurobiol 115: 25-44, 2014.

10. Xue $M$ and Yong VW: Neuroinflammation in intracerebral haemorrhage: Immunotherapies with potential for translation. Lancet Neurol 19: 1023-1032, 2020.

11. Chen JH, Yang LK, Chen L, Wang YH, Wu Y, Jiang BJ, Zhu J and Li PP: Atorvastatin ameliorates early brain injury after subarachnoid hemorrhage via inhibition of AQP4 expression in rabbits. Int J Mol Med 37: 1059-1066, 2016.

12. Bao WD, Zhou XT, Zhou LT, Wang F, Yin X, Lu Y, Zhu LQ and Liu D: Targeting miR-124/Ferroportin signaling ameliorated neuronal cell death through inhibiting apoptosis and ferroptosis in aged intracerebral hemorrhage murine model. Aging Cell 19: e13235, 2020.

13. Gautam J, Xu L, Nirwane A, Nguyen B and Yao Y: Loss of mural cell-derived laminin aggravates hemorrhagic brain injury. J Neuroinflammation 17: 103, 2020. 
14. Karuppagounder SS, Alim I, Khim SJ, Bourassa MW, Sleiman SF, John R, Thinnes CC, Yeh TL, Demetriades M, Neitemeier S, et al: Therapeutic targeting of oxygen-sensing prolyl hydroxylases abrogates ATF4-dependent neuronal death and improves outcomes after brain hemorrhage in several rodent models. Sci Transl Med 8: 328ra329, 2016.

15. Chen J, Zhang C, Yan T, Yang L, Wang Y, Shi Z, Li M and Chen Q: Atorvastatin ameliorates early brain injury after subarachnoid hemorrhage via inhibition of pyroptosis and neuroinflammation. J Cell Physiol: Mar 31, 2021 (Epub ahead of print). doi: 10.1002/jep.30351.

16. Wang T, Nowrangi D, Yu L, Lu T, Tang J, Han B, Ding Y, Fu F and Zhang JH: Activation of dopamine D1 receptor decreased NLRP3-mediated inflammation in intracerebral hemorrhage mice. J Neuroinflammation 15: 2, 2018.

17. Wang M, Ye X, Hu J, Zhao Q, Lv B, Ma W, Wang W, Yin H, Hao Q, Zhou C, et al: NOD1/RIP2 signalling enhances the microglia-driven inflammatory response and undergoes crosstalk with inflammatory cytokines to exacerbate brain damage following intracerebral haemorrhage in mice. J Neuroinflammation 17: 364, 2020.

18. Chen S, Peng J, Sherchan P, Ma Y, Xiang S, Yan F, Zhao H, Jiang Y, Wang N, Zhang JH and Zhang H: TREM2 activation attenuates neuroinflammation and neuronal apoptosis via PI3K/Akt pathway after intracerebral hemorrhage in mice J Neuroinflammation 17: 168, 2020.

19. Chen AQ, Fang Z, Chen XL, Yang S, Zhou YF, Mao L, Xia YP, Jin HJ, Li YN, You MF, et al: Microglia-derived TNF- $\alpha$ mediates endothelial necroptosis aggravating blood brain-barrier disruption after ischemic stroke. Cell Death Dis 10: 487, 2019.

20. Chu X, Wu X, Feng H, Zhao H, Tan Y, Wang L, Ran H, Yi L, Peng Y, Tong H, et al: Coupling between Interleukin-1R1 and necrosome complex involves in hemin-induced neuronal necroptosis after intracranial hemorrhage. Stroke 49: 2473-2482, 2018

21. Su X, Wang H, Kang D, Zhu J, Sun Q, Li T and Ding K Necrostatin-1 ameliorates intracerebral hemorrhage-induced brain injury in mice through inhibiting RIP1/RIP3 pathway. Neurochem Res 40: 643-650, 2015.

22. Lule S, Wu L, Sarro-Schwartz A, Edmiston Iii WJ, Izzy S, Songtachalert T, Ahn SH, Fernandes ND, Jin G, Chung JY, et al: Cell-specific activation of RIPK1 and MLKL after intracerebral hemorrhage in mice. J Cereb Blood Flow Metab: Nov 19, 2020 (Epub ahead of print). doi: 10.1177/0271678X20973609.

23. Weiping L, Dong Z, Zhen H, Patten A, Dash A and Malhotra M: Efficacy, safety, and tolerability of adjunctive perampanel in patients from China with focal seizures or generalized tonic-clonic seizures: Post hoc analysis of phase III double-blind and open-label extension studies. CNS Neurosci Ther 27: 330-340, 2021.

24. Chen T, Liu WB, Qian X, Xie KL and Wang YH: The AMPAR antagonist perampanel protects the neurovascular unit agains traumatic injury via regulating Sirt3. CNS Neurosci Ther 27: 134-144, 2021

25. Dohare P, Zia MT, Ahmed E, Ahmed A, Yadala V, Schober AL, Ortega JA, Kayton R, Ungvari Z, Mongin AA and Ballabh P: AMPA-kainate receptor inhibition promotes neurologic recovery in premature rabbits with intraventricular hemorrhage. J Neurosci 36: 3363-3377, 2016.

26. Wright SK, Wilson MA, Walsh R, Lo WB, Mundil N, Agrawal S, Philip S, Seri S, Greenhill SD and Woodhall GL: Abolishing spontaneous epileptiform activity in human brain tissue through AMPA receptor inhibition. Ann Clin Transl Neurol 7: 883-890, 2020 .

27. Chen T, Dai SH, Jiang ZQ, Luo P, Jiang XF, Fei Z, Gui SB and Qi YL: The AMPAR antagonist perampanel attenuates traumatic brain injury through anti-oxidative and anti-inflammatory activity. Cell Mol Neurobiol 37: 43-52, 2017.

28. Chen T, Yang LK, Zhu J, Hang CH and Wang YH: The AMPAR antagonist perampanel regulates neuronal necroptosis via Akt/GSK3 $\beta$ signaling after acute traumatic injury in cortical neurons. CNS Neurol Disord Drug Targets: Oct 1, 2020 (Epub ahead of print). doi: 10.2174/1871527319666201001110937.

29. Wang L, Wang L, Shi X and Xu S: Chlorpyrifos induces the apoptosis and necroptosis of L8824 cells through the ROS/PTEN/PI3K/AKT axis. J Hazard Mater 398: 122905, 2020

30. Guido C, Panza S, Santoro M, Avena P, Panno ML, Perrotta I, Giordano F, Casaburi I, Catalano S, De Amicis F, et al: Estrogen receptor beta $(\mathrm{ER} \beta)$ produces autophagy and necroptosis in human seminoma cell line through the binding of the Sp1 on the phosphatase and tensin homolog deleted from chromosome 10 (PTEN) promoter gene. Cell Cycle 11: 2911-2921, 2012.
31. Gao X, Xiong Y, Li Q, Han M, Shan D, Yang G, Zhang S, Xin D, Zhao R, Wang Z, et al: Extracellular vesicle-mediated transfer of miR-21-5p from mesenchymal stromal cells to neurons alleviates early brain injury to improve cognitive function via the PTEN/Akt pathway after subarachnoid hemorrhage. Cell Death Dis 11: 363,2020 .

32. Deng S, Sherchan P, Jin P, Huang L, Travis Z, Zhang JH, Gong Y and Tang J: Recombinant CCL17 enhances hematoma resolution and activation of CCR4/ERK/Nrf2/CD163 signaling pathway after intracerebral hemorrhage in mice. Neurotherapeutics 17 : 1940-1953, 2020.

33. Chen J, Xuan Y, Chen Y, Wu T, Chen L, Guan H, Yang S, He J, Shi D and Wang Y: Netrin-1 alleviates subarachnoid haemorrhage-induced brain injury via the PPAR $\gamma / \mathrm{NF}-\kappa \mathrm{B}$ signalling pathway. J Cell Mol Med 23: 2256-2262, 2019.

34. Chen JH, Wu T, Xia WY, Shi ZH, Zhang CL, Chen L, Chen QX and Wang YH: An early neuroprotective effect of atorvastatin against subarachnoid hemorrhage. Neural Regen Res 15: 1947-1954, 2020

35. Mo Y, Duan L, Yang Y, Liu W, Zhang Y, Zhou L, Su S, Lo PC, Cai J, Gao L, et al: Nanoparticles improved resveratrol brain delivery and its therapeutic efficacy against intracerebral hemorrhage. Nanoscale 13: 3827-3840, 2021.

36. Chen JH, Wu T, Yang LK, Chen L, Zhu J, Li PP, Hu X and Wang YH: Protective effects of atorvastatin on cerebral vessel autoregulation in an experimental rabbit model of subarachnoid hemorrhage. Mol Med Rep 17: 1651-1659, 2018.

37. Livak KJ and Schmittgen TD: Analysis of relative gene expression data using real-time quantitative PCR and the 2(-Delta Delta C(T)) method. Methods 25: 402-408, 2001.

38. Kim JE, Park H, Lee JE, Kim TH and Kang TC: PTEN is required for the anti-epileptic effects of AMPA receptor antagonists in chronic epileptic rats. Int J Mol Sci 21: 5643, 2020.

39. Mazzocchetti P, Mancini A, Sciaccaluga M, Megaro A, Bellingacci L, Di Filippo M, Cesarini EN, Romoli M, Carrano N, Gardoni F, et al: Low doses of Perampanel protect striatal and hippocampal neurons against in vitro ischemia by reversing the ischemia-induced alteration of AMPA receptor subunit composition. Neurobiol Dis 140: 104848, 2020.

40. De Caro C, Cristiano C, Avagliano C, Cuozzo M, La Rana G, Aviello G, De Sarro G, Calignano A, Russo E and Russo R: Analgesic and Anti-inflammatory effects of perampanel in acute and chronic pain models in mice: Interaction with the cannabinergic system. Front Pharmacol 11: 620221, 2021.

41. Aida V, Niedzielko TL, Szaflarski JP and Floyd CL: Acute administration of perampanel, an AMPA receptor antagonist, reduces cognitive impairments after traumatic brain injury in rats. Exp Neurol 327: 113222, 2020.

42. Vandenabeele P, Galluzzi L, Vanden Berghe T and Kroemer G: Molecular mechanisms of necroptosis: An ordered cellular explosion. Nat Rev Mol Cell Biol 11: 700-714, 2010.

43. Chen T, Zhu J, Wang YH and Hang CH: Arc silence aggravates traumatic neuronal injury via mGluR1-mediated ER stress and necroptosis. Cell Death Dis 11: 4, 2020.

44. Bao Z, Fan L, Zhao L, Xu X, Liu Y, Chao H, Liu N, You Y, Liu Y, Wang $X$ and Ji J: Silencing of A20 aggravates neuronal death and inflammation after traumatic brain injury: A potential trigger of necroptosis. Front Mol Neurosci 12: 222, 2019.

45. Laird MD, Wakade C, Alleyne CH Jr and Dhandapani KM: Hemin-induced necroptosis involves glutathione depletion in mouse astrocytes. Free Radic Biol Med 45: 1103-1114, 2008.

46. Shen H, Liu C, Zhang D, Yao X, Zhang K, Li H and Chen G: Role for RIP1 in mediating necroptosis in experimental intracerebral hemorrhage model both in vivo and in vitro. Cell Death Dis 8: e2641, 2017.

47. Zhang Y, Li M, Li X, Zhang H, Wang L, Wu X, Zhang H and Luo Y: Catalytically inactive RIP1 and RIP3 deficiency protect against acute ischemic stroke by inhibiting necroptosis and neuroinflammation. Cell Death Dis 11: 565, 2020.

48. Yuan J, Amin P and Ofengeim D: Necroptosis and RIPK1-mediated neuroinflammation in CNS diseases. Nat Rev Neurosci 20: 19-33, 2019.

49. Linkermann A and Green DR: Necroptosis. N Engl J Med 370 $455-465,2014$

50. Xu X, Chua CC, Kong J, Kostrzewa RM, Kumaraguru U, Hamdy RC and Chua BH: Necrostatin-1 protects against glutamate-induced glutathione depletion and caspase-independent cell death in HT-22 cells. J Neurochem 103: 2004-2014, 2007. 
51. Liu L, Liu Y, Cheng X and Qiao X: The alleviative effects of quercetin on Cadmium-induced necroptosis via inhibition ROS/iNOS/NF- $\kappa$ B pathway in the Chicken brain. Biol Trace Elem Res 199: 1584-1594, 2021.

52. Wang KJ, Meng XY, Chen JF, Wang KY, Zhou C, Yu R and Ma Q: Emodin induced necroptosis and inhibited glycolysis in the renal cancer cells by enhancing ROS. Oxid Med Cell Longev 2021: 8840590, 2021.

53. Tian Q, Qin B, Gu Y, Zhou L, Chen S, Zhang S, Zhang S, Han Q, Liu $\mathrm{Y}$ and $\mathrm{Wu} \mathrm{X}$ : ROS-mediated necroptosis is involved in iron overload-induced osteoblastic cell death. Oxid Med Cell Longev 2020: 1295382, 2020.

54. Liu X, Zhang N, Wang D, Zhu D, Yuan Q, Zhang X, Qian L, Niu H, Lu Y, Ren G, et al: Downregulation of reticulocalbin-1 differentially facilitates apoptosis and necroptosis in human prostate cancer cells. Cancer Sci 109: 1147-1157, 2018.

55. Zhao D, Qin XP, Chen SF, Liao XY, Cheng J, Liu R, Lei Y, Zhang ZF and Wan Q: PTEN inhibition protects against experimental intracerebral hemorrhage-induced brain injury through PTEN/E2F1/3-catenin pathway. Front Mol Neurosci 12: 281, 2019.
56. Chang N,El-Hayek YH, Gomez E and Wan Q: Phosphatase PTEN in neuronal injury and brain disorders. Trends Neurosci 30: 581-586, 2007.

57. Huang H, Hu C, Xu L, Zhu X, Zhao L and Min J: The effects of hesperidin on neuronal apoptosis and cognitive impairment in the sevoflurane anesthetized rat are mediated through the PI3/Akt/PTEN and nuclear Factor $-\kappa \mathrm{B}(\mathrm{NF}-\kappa \mathrm{B})$ signaling pathways. Med Sci Monit 26: e920522, 2020

58. Huang SY, Sung CS, Chen WF, Chen CH, Feng CW, Yang SN, Hung HC, Chen NF, Lin PR, Chen SC, et al: Involvement of phosphatase and tensin homolog deleted from chromosome 10 in rodent model of neuropathic pain. J Neuroinflammation 12: 59, 2015.

(7)(3) This work is licensed under a Creative Commons

CY AC AD Attribution-NonCommercial-NoDerivatives 4.0 International (CC BY-NC-ND 4.0) License. 